June 1995

\title{
Non-Neuroleptic Pharmacotherapy of Schizophrenia
}

\author{
Sajiv John, MD \\ University of Chicago
}

Atul Mahableshwarkar, MD

Finch University of Health Sciences in Chicago

Follow this and additional works at: https://jdc.jefferson.edu/jeffjpsychiatry

Part of the Psychiatry Commons

Let us know how access to this document benefits you

\section{Recommended Citation}

John, MD, Sajiv and Mahableshwarkar, MD, Atul (1995) "Non-Neuroleptic Pharmacotherapy of Schizophrenia," Jefferson Journal of Psychiatry. Vol. 12 : Iss. 2 , Article 6.

DOI: https://doi.org/10.29046/JJP.012.2.002

Available at: https://jdc.jefferson.edu/jeffjpsychiatry/vol12/iss2/6

This Article is brought to you for free and open access by the Jefferson Digital Commons. The Jefferson Digital Commons is a service of Thomas Jefferson University's Center for Teaching and Learning (CTL). The Commons is a showcase for Jefferson books and journals, peer-reviewed scholarly publications, unique historical collections from the University archives, and teaching tools. The Jefferson Digital Commons allows researchers and interested readers anywhere in the world to learn about and keep up to date with Jefferson scholarship. This article has been accepted for inclusion in Jefferson Journal of Psychiatry by an authorized administrator of the Jefferson Digital Commons. For more information, please contact: JeffersonDigitalCommons@jefferson.edu. 


\title{
Non-Neuroleptic Pharmacotherapy of Schizophrenia
}

\author{
Sajiv John, M.D. \\ Atul Mahableshwarkar, M.D.
}

\begin{abstract}
Patients with schizophrenia are typically treated with a neuroleptic and some form of psychosocial intervention. In spite of optimum treatment, up to one-third of patients continue to remain severely disabled due to persistent positive or negative symptoms. A variety of drugs have been tried as alternatives or additions to traditional neuroleptics in these patients. This paper is a review of these nonneuroleptic treatment alternatives and an attempt to establish some guidelines for their use.
\end{abstract}

The current approach to treatment of patients with schizophrenia is a combination of medication and psychosocial intervention; this approach has yielded the best results (1). The efficacy of medication is well documented (2), yet up to $30 \%$ of patients who have had optimum trials of neuroleptics continue to experience positive or negative symptoms, or display uncontrolled behavior (2). Patients who do not respond adequately to neuroleptics may be severely impaired due to persistent symptoms. They may also develop significant side effects like tardive dyskinesia. It is, therefore, extremely important that alternative therapies be developed to bring these symptoms under control. Several trials involving nonneuroleptic agents have been carried out with varying results. Can these results be extended to involve all neuroleptic resistant patients? How does one decide which patient to match with which drug? This paper is an attempt to try to answer these questions and also to review the therapeutic modalities available for the neuroleptic resistant patient.

Kane et al (3) defined neuroleptic resistance as occurring in a patient who continued to experience significant impairment from symptoms of the illness in spite of trials of at least 3 different neuroleptics, from 2 different chemical classes, for six weeks each, in doses of up to $1,500 \mathrm{mgs}$ of chlorpromazine equivalent, over the last 5 years, after organic pathology had been ruled out. This definition of resistance appears to be comprehensive and is widely used. Should blood levels be a part of the definition of resistance? At this stage, testing for blood levels of neuroleptics is not routinely used in clinical settings because both actual results and testing techniques

Sajiv John, M.D. is a PGY-3 resident in the Department of Psychiatry at the University of Chicago. Atul Mahableshwarkar, M.D. is an Instructor in the Department of Psychiatry at Finch University of Health Sciences in Chicago. 
have not been consistent. Future definitions of neuroleptic resistance may well include blood level criteria.

The term neuroleptic originated from "neuroleptanalgesia"-a form of short acting anesthesia combining an opiate derivative, fentanyl, and an antipsychotic, droperidol (4). The term has since come to refer to an agent that has both an antipsychotic effect and an extrapyramidal side effect profile (EPS). This review focuses on drugs that are not strictly neuroleptics-specifically, drugs that have been shown to have antipsychotic effect, but no significant EPS profile.

\section{Lithium}

Studies have shown that adding lithium to a neuroleptic can help treatment resistant patients. We looked at several which were either important reviews (5), or studies that have used RDC criteria (6) and single blind (7) or double blind designs $(8,9)$ with crossover phases using placebo, for a total of at least four weeks each. The usual serum levels of lithium in these trials have ranged from 0.9-1.2 meqs/liter and they have lasted from 3-5 weeks. Improvement in patients was documented in the following areas: psychotic symptoms, cooperation, social competence, neatness, irritability, and excitement (9). Lithium alone was inferior to neuroleptics in the acutely ill patient, though it is useful as an adjunct in schizophrenia or schizoaffective disorder $(5,9)$. Affective symptoms need not be present for improvement to occur, though presence of affective symptoms may predict a better response to treatment with lithium. Response to lithium does not mean a need to change the diagnosis to a mood disorder. Lithium may decrease chronic symptoms and may decrease the rate of relapse by as much as $30 \%$ in schizoaffective illness (8). There were a few early reports of a reversible delirium when lithium was combined with high doses of neuroleptics (10). These have been shown to be completely reversible when the drug was discontinued and now appear to have been cases of neuroleptic malignant syndrome.

In conclusion, adding lithium to neuroleptics in treatment resistant patients can result in decreased psychotic symptoms, excitement, irritability and possibly rates of relapse. Presence of affective symptoms appears to predict better response in these patients.

\section{Benzodiazepines}

Our review of the literature revealed 15 double-blind studies of the use of benzodiazepines in schizophrenia. Only four (11-14) used DSM-III (15) and/or RDC criteria for diagnosis, had double-blind designs with placebo crossovers and lasted from 2-8 weeks. Typically benzodiazepines are used in conjunction with neuroleptics, and studies have shown decreased hostility, tension, excitement, and increased spontaneous social engagement $(11,12)$. Specific benzodiazepines studied include alprazolam (12,14), diazepam, chlordiazepoxide (13,14), and estazolam (11). Longer acting drugs like diazepam and chlordiazepoxide are safer, as they generally have 
milder withdrawal symptoms. Benzodiazepines have usually been used during exacerbations of psychosis to decrease agitation. Benzodiazepines must be used carefully due to the potential problems of abuse, withdrawal symptoms including seizures and occasional social disinhibition.

In addition to clinically available benzodiazepines, GABA mimetic agents and partial benzodiazepine agonists have also been studied experimentally. In theory, these agents should produce anxiolytic and anticonvulsant effects without the sedative and muscle relaxant effects of benzodiazepines. It is also anticipated that they might produce decreased CNS depressant activity with reduced toxicity in the overdose situation, lack of potentiation of alcohol effects, and reduced physical dependence and abuse liability. Muscimol, a GABA mimetic, was found to aggravate psychotic symptoms, while others, including tetrahydroisoxazolopyridinol, gammaacetylenic GABA, gamma vinyl GABA, and progabide, have been shown to produce no effect in schizophrenia. Partial agonists, including abecarnil, alpidem, divalon, and bretazenil, have been studied, with only bretazenil (up to $4.5 \mathrm{mgs} /$ day) producing any effect. It produced a $40 \%$ decrease in BPRS scores, effects on both positive and negative symptoms, no EPS and mild sedation when given to 116 patients for 3 weeks (26). Benzodiazepines have also proved useful in treating some of the side effects of neuroleptics like akathisia, tardive dyskinesia, and dystonia (2). Unfortunately, most studies of the use of benzodiazepines in patients with schizophrenia have used very small sample sizes, thus limiting the conclusions that can be drawn from them.

In conclusion, benzodiazepines can be effective in treating certain neuroleptic side effects, and they may also have a role to play when combined with neuroleptics in patients who display anxiety, psychosis, or agitation not responding to conventional neuroleptics alone. GABA mimetics and partial benzodiazepine agonists have not consistently been shown to be effective in studies to date. However, the one encouraging report on bretazenil and the much better side effect profile of the group in general make further research in this area imperative.

\section{Carbamazepine}

Trials with carbamazepine in schizophrenia are fairly new and the drug is typically used in addition to neuroleptics. Of 5 double-blind studies of the use of carbamazepine in patients with schizophrenia, three are superior, utilizing DSM-III or RDC criteria for the diagnosis of schizophrenia, the crossover format with placebo, standard rating scales, and serum carbamazepine levels between 5-18 mcgs $/ \mathrm{ml}$ (16-18). Trials have lasted 4-6 weeks. In neuroleptic refractory patients, carbamazepine has been shown to decrease excitement, mania like symptoms, suspiciousness, violence, and aggression. Carbamazepine has also been shown to be useful in nonepileptic schizophrenic patients with temporal lobe EEG abnormalities, with such patients showing decreased aggressive acts and improved self-control in interpersonal situations (17).

These studies seem to suggest that any effect of carbamazepine on psychotic symptoms is modest. The main benefit of carbamazepine in patients with schizophre- 
nia may be in decreasing aggression, overactivity, and improving control in interpersonal situations.

\section{Propranolol}

Initial trials of propranolol in schizophrenia were received with enthusiasm, however later work has not been as encouraging. Propranolol has been used in combination with neuroleptics, initially the racemic (d-l) form and later the dextro (d) form, both of which appear to have some antipsychotic action (19-21). Doses have varied from 1000-3000 mgs per day; these doses are high enough to leave the patient at risk for serious cardiovascular or respiratory side effects. Of 9 double-blind studies available, the three cited used 35 or more patients, made diagnoses on the Present State Examination (PSE) (22) and used more than one standard rating scale for follow-up. Propranolol has been shown to increase blood levels of chlorpromazine and thioridazine, but not haloperidol, and to have a beneficial effect on akathisia (20). Some authors have postulated these as the mechanisms of action, instead of a primary antipsychotic effect (2).

These studies suggest that any antipsychotic effect of propranolol is at best slight and may be related to its beneficial pharmacokinetic interactions or to a decrease in akathisia. This, along with its side effect profile, make it a limited adjunct for patients with treatment resistant schizophrenia.

\section{Clozapine and Other Novel Antipsychotic Drugs}

Clozapine first appeared in the 1970's in Europe as an antipsychotic structurally related to loxapine and effective in a subgroup of treatment resistant patients. It then disappeared for several years following several reports of agranulocytosis occurring with the drug, but has recently emerged again following several carefully conducted studies $(2,3,23-26)$. Up to $30 \%$ of treatment resistant patients have shown substantial improvement in positive and negative symptoms and on global rating scales when given clozapine in doses ranging from 300-600 mgs per day for up to 6 weeks. The drug seems to have mesolimbic and cortical specificity, therefore it is associated with a very low incidence of Parkinsonian symptoms and tardive dyskinesia. It appears to act by influencing multiple neurotransmitter systems. It has an anticholinergic and antihistaminic effect, is an antagonist at 5HT2 and 5HT3 receptors, has an antiadrenergic action, a D1 and D3 along with some D2 blocking action at dopamine receptors and also increases dopamine release in the mesocortical system. Its effect on 5HT2 and 5HT3 receptors and its ability to increase dopamine release in the mesocortical systems may underlie its effects on negative systems. A major side effect includes agranulocytosis, which was initially seen in up to $13 \%$ of patients, and which is now believed to occur in about $1.6 \%$ of patients on the drug for more than one year. This effect is reversible if the drug is discontinued. Weekly white blood cell counts are advised and the maximum risk period is believed to be between 6 weeks and 6 months. Other side effects include seizures in doses 
greater than $600 \mathrm{mgs}$ per day, hypertension and sialorrhea, the last two being atypical for an agent with antiadrenergic and anticholinergic action.

\section{Antidepressants}

"Depression" in schizophrenia is common with up to $50 \%$ of first episode patients and $30 \%$ of chronic patients meeting criteria for major depression and $10 \%$ of schizophrenics dying of suicide (27). However, what constitutes "depression" in schizophrenics can be difficult to assess as organic factors, including anemias, cancers, endocrine and neurological disorders and medications, negative symptoms, drug induced akinesia and akathisia, cognitive changes and partial insight into the nature and consequences of the illness are all capable of mimicking depression. Depression may also be prominent in the prodrome of psychotic relapse and in schizoaffective disorder. Two major articles have reviewed the role of antidepressants (tricyclics, MAO inhibitors and possibly lithium) in schizophrenia $(27,28)$. Further, Siris (29) has very recently reviewed the assessment and treatment of depression in schizophrenia. These reviews suggest that antidepressants have a role in the treatment of depression in schizophrenia after the confounding factors mentioned have been ruled out.

Antidepressants have produced better results in outpatients rather than in inpatients and in patients who are not actively psychotic. Most studies have used doses comparable to those used in primary depression, and trials have lasted at least six weeks. Direct comparisons of different tricyclic antidepressants or of tricyclics with other antidepressants have not been reported. Siris (29) recommends that the dose of the antidepressant be gradually increased and that they be used in combination with ongoing neuroleptic and antiparkinsonian treatment. Long-term maintenance treatment may be beneficial for the patient who responds favorably initially. Antidepressants have not been shown to be effective for negative symptoms. Most reported double blind placebo controlled trials have involved tricyclic antidepressants. However, scattered preliminary reports suggest that monoamine oxidase inhibitors and selective serotonin reuptake inhibitors may be effective as well (29). It should be noted that when tricyclics are used with antipsychotics, the blood levels of both drugs can increase as can the anticholinergic effect. Therefore, any improvement noted may be spurious.

\section{L-Dopa and Reserpine}

Our review revealed four studies assessing the role of L-dopa in schizophrenia, most of which were carried out in the 1970's and in which patients were diagnosed without using standardized criteria. A further limitation is that follow-up has been based on a global clinical impression and not standardized rating scales. Trials have used doses between 300-2000 mgs per day for 6-8 weeks, usually combined with neuroleptics and a peripheral dopadecarboxylase inhibitor. Studies $(2,30)$ suggest that chronic patients with negative symptoms, usually hospitalized and refractory to 
treatment, can show some increased activity, alertness, social contact and motivation. Side effects of L-Dopa in this population significantly limit its use. These include worsening of psychotic symptoms, agitation, and drug-induced dyskinesias. More research is needed as L-Dopa may be useful in patients with negative symptoms, and this subgroup has proved refractory to most drug trials.

Reserpine $(2,31)$ was the first drug to prove effective in treating patients with psychosis and was widely used prior to the introduction of neuroleptics in the 1950's. Our review of the literature revealed a total of 8 studies assessing the effectiveness of reserpine in schizophrenia. The best of these (31) used a total of 120 patients, lasted 6 months and compared reserpine $2 \mathrm{mgs} /$ day versus chlorpromazine $200 \mathrm{mgs} /$ day and placebo. In doses of 2-12 mgs per day for up to 6 weeks, patients have shown modest improvement in positive symptoms and interpersonal functioning. Significant side effects of reserpine include depression, hypotension, and exacerbations of asthma and peptic ulcer. Since both reserpine and antipsychotics act by decreasing DA transmission, it may not be effective in neuroleptic resistant patients. The major limitation here is the lack of recent literature and the side effects of the drug which limit its usefulness in schizophrenia.

\section{Other Non-Neuroleptic Drugs}

Many other agents have been tried as alternative treatments in neuroleptic resistant schizophrenics. For many like baclofen (32), betaendorphin (33), calcium channel antagonists (34), cholecystokinin-like agents (35), megavitamins (36), bromocriptine (37), apomorphine (38), naloxone and naltrexone $(39,40)$, and thyrotropin releasing hormone (41), the majority of controlled studies have not documented sustained efficacy. For others like valproate (42), vasopressin (43), and clonidine (44), either double blind data are too preliminary, or side effects like postural hypotension or fluid retention do not allow even preliminary conclusions.

\section{Conclusions}

Our review of the literature suggests that the best way to manage the treatment resistant schizophrenic is to identify the persisting symptoms and then apply various treatment options. For patients with persisting positive symptoms, drugs to be considered include clozapine, lithium, benzodiazepines and carbamazepine. For patients with mainly negative symptoms, drugs to be considered include clozapine and alprazolam. If patients display predominant aggression and poor impulse control secondary to positive symptoms, treat with drugs shown useful for positive symptoms. If aggression and poor impulse control occurs independently, drugs that can be used include carbamazepine, beta blockers, lithium, and possibly serotonergic agents in light of evidence linking serotonin dysfunction with violence and aggression. It is best to avoid benzodiazepines in this group as they can lead to disinhibited behavior. Figure I below summarizes the role of non-neuroleptic pharmacotherapy in neuroleptic resistant schizophrenic patients. 
Define schizophrenia using standardized criteria such as DSM-III-R

dentify side-effects and test:

1. Parkinsonism-anticholinergics (tremor); amantadine (rigidity and akinesia)

2. Akathisia-benzodizapines or beta blockers

3. Tardive dyskinesia-adjust dose of antipsychotics/anticholinergics, benzodiazepines, tetrabenazine, etc. define using comprehe
such as Kane et al (3)

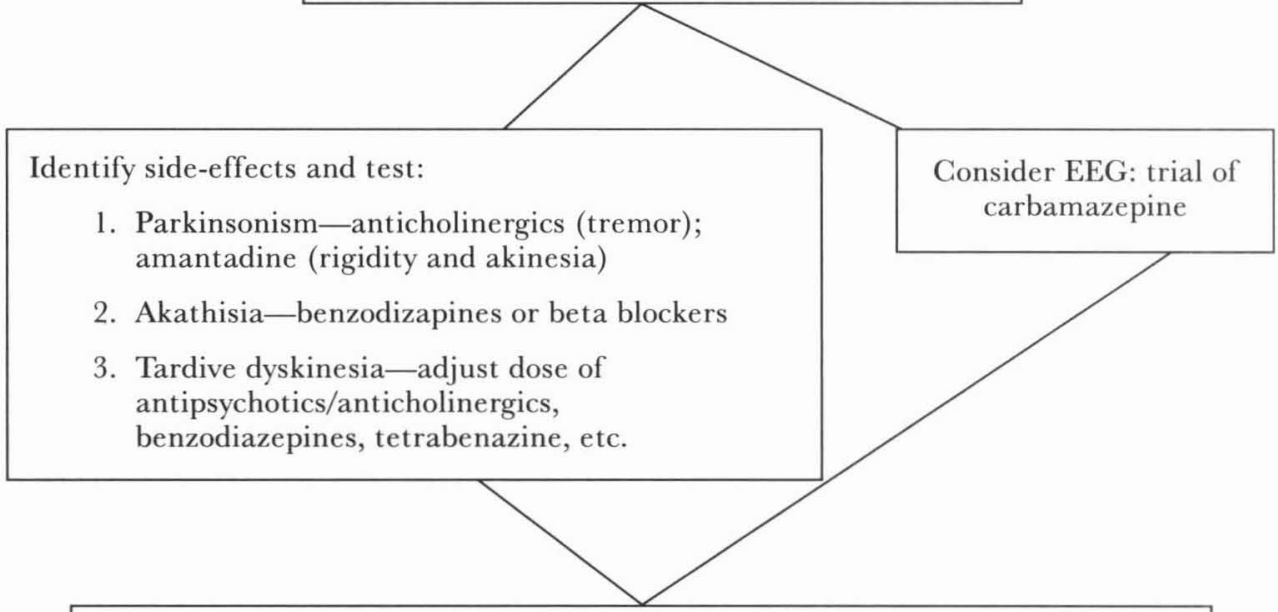

Resistance-define using comprehensive criteria,

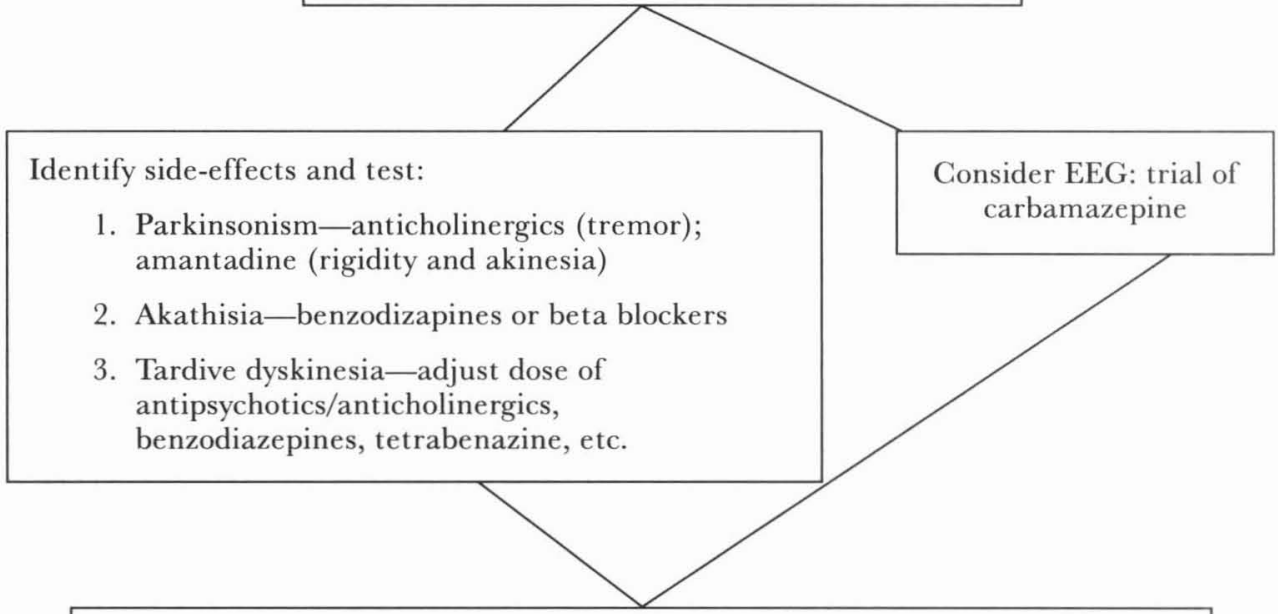

Symptoms persisting-identify specific target symptoms and add one of the drugs below, always combining with psychosocial therapy.

\section{Symptoms}

Positive

Trial of

lithium, ECT,

clozapine, in that

order.

Also consider carbamazepine

and

benzodiazepines.

below, always combining with psychosocial therapy.

sider EEG: trial of

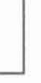


There are several general principles to be kept in mind when using these agents. With the exception of clozapine, most should be combined with neuroleptics. They should be introduced gradually, and side effects should be monitored and treated early. Drugs should be changed, one at a time if needed, after identifying specific target symptoms and monitoring changes carefully. Always discuss the risks and benefits with the patient and carefully document it in the chart (2,25). Essentially, these are the principles of good pharmacotherapy.

Schizophrenia, especially treatment resistant illness, is hard to treat. Some options for pharmacotherapy do exist. These options can be implemented logically and are best done after identifying specific target symptoms. Further research in this area is clearly needed.

\section{REFERENCES}

1. Liberman RP, Mueser KT: Schizophrenia: Psychosocial treatment. In: Kaplan HI, Sadock BJ, Eds. Comprehensive Textbook of Psychiatry. Vol. 1, 5th ed. Baltimore, MA: Williams and Wilkins Company, 1989

2. Christison GW, Kirch DG, Wyatt RJ: When symptoms persist: Choosing among alternative somatic treatments for schizophrenia. Schiz. Bulletin 1991; 17(2):217-245

3. Kane J, Honigfeld G, Singer J, Meltzer HY and The Clozaril Collaborative Study Group: Clozapine for the treatment-resistant schizophrenic. Arch of Gen Psych 1988; 45:789-796

4. Dipalma JR Ed. Drill's pharmacology in medicine, 2nd ed. Pp. 182-183, 215. McGraw Hill Book Co., 1982

5. Delva MJ, Letemendia FJJ: Lithium treatment in schizophrenic and schizo-affective disorders. Brit JI of Psych 1982; 144:387-400

6. Spitzer RL, Endicott J, Robins E: Research Diagnostic Criteria: Rationale and reliability. Arch of Gen Psych 1978; 35:773-782

7. Collins PJ, Lerkin EP, Shubsachs APW: Lithium carbonate in chronic schizophrenia-A brief trial of lithium carbonate added to neuroleptics for treatment of resistant schizophrenic patients. Acta Psych Scand 1991; 84:150-154

8. Lerner Y, Mintzer Y, Shestatsky M: Lithium combined with haloperidol in schizophrenia patients. Brit JI of Psych 1988; 153:359-362

9. Carmen JS, Bigelow LB, Wyatt RJ: Lithium combined with neuroleptics in chronic schizophrenic and schizoaffective patients. JI of Clin Psych 1981; 42:124-128

10. Cohen WJ, Cohen NH: Lithium carbonate, haloperidol and irreversible brain damage. JI of the Am Med Assn 1974; 230:1283-1287

11. Lingaerde $\mathrm{O}$ : Effect of estazolam in patients with auditory hallucinations. Acta Psych Scand 1982; 65:339-354

12. Wolkowitz DM, Picker D, Donan AR, Brien A, Tarrell J, Paul SM: Combination alprazolam-neuroleptic treatment of the positive and negative symptoms of schizophrenia. Am JI of Psych 1986; 143:85-87

13. Jimerson DC, Van Kammen DP, Post RM, Docherty JP, Bunney WE Jr: Diazepam in schizophrenia: A preliminary double blind trial. Am JI of Psych 1982; 139:489-491

14. Csernansky JG, Riney SJ, Lombrozo LI, Overall JE, Hollister LE: Double blind comparison of alprazolam, diazepam and placebo for the treatment of negative schizophrenic symptoms. Arch of Gen Psych 1988; 45:655-659 
15. American Psychiatric Association. DSM-III: Diagnostic and Statistical Manual of Mental Disorders, 3rd Ed., Washington, DC: The Association, 1980

16. Okuma T, Yamashita I, Takahashi R, Itoh H, Kurihara M, Otsuki S, Watanabe S, Nazamura H, Inanaga K: A double blind study of adjunctive carbamazepine versus placebo on excited states of schizophrenia and schizoaffective disorders. Acta Psych Scand 1989; 80:250-259

17. Neppe V: Carbamazepine as adjunctive treatment in nonepileptic chronic inpatients with EEG temporal lobe abnormalities. JI of Clin Psych 1983; 44:326-331

18. Klein E, Bental E, Lerer B, Belmaker RH: Carbamazepine and haloperidol vs placebo and haloperidol in excited psychoses. Arch of Gen Psych 1984; 41:165-170

19. Yorkston NJ, Zaki SA, Weller MP, GruzelierJH, Hirsch SR: DL propranolol and chlorpromazine following admission for schizophrenia: A controlled comparison. Acta Psych Scand $1981 ; 63: 13-27$

20. Manchanda R, Hirsch SR: Does propranolol have an antipsychotic effect? A placebo controlled study in acute schizophrenia. Brit JI of Psych 1986; 148:701-707

21. Donaldson SR, Gelenberg AJ, Baldessarini RJ: Alternative treatments for schizophrenic psychoses. In: Arieti S, Ed., American Handbook of Psychiatry. New York: Basic Books, 1986

22. Wing JK, Cooper JE, Sartorius N: The Measurement and Classification of Psychiatric Symptoms. Cambridge, MA: Cambridge University Press, 1974

23. Fisher-Cornelssen KA, Ferner VJ: An example of European multi centre trials: Multispectral analysis of clozapine. Psychopharm Bulletin 1976; 12:34-39

24. Safferman A, Lieberman JA, Kane JM, Szymanski S, Kinon B: Update on the clinical efficacy and side effects of clozapine. Schiz Bulletin 1991; 17(2):247-260

25. Meltzer HY: The mechanism of action of novel antipsychotic drugs. Schiz Bulletin 1991; $17(2): 263-280$

26. Gerlach J: New antipsychotics: Classification, efficacy, and adverse effects. Schiz Bulletin 1991; 17(2):289-309

27. Siris SG, Van Kammen DP, Docherty JP: Use of antidepressant drugs in schizophrenia. Arch of Gen Psych 1978; 35:1368-1377

28. Plasky P: Antidepressant usage in schizophrenia. Schiz Bulletin 1991; 17(4):649-656

29. Siris SG: Assessment and treatment of depression in schizophrenia. Psych Annals 1994; 24(9):463-467

30. Inanaga K, Nakazawa T, Inoue K, Tachibana H, Oshima M, Kotorii T, Tanaka M, Ogawa N: Double-blind controlled study of L-Dopa therapy in schizophrenia. Folia Psych et Neuro Jap 1975; 29:123-143

31. Shawver JR, Gorham DR, Leskin LW, Good WW, Kabnick DE: Comparison of chlorpromazine and reserpine in maintenance drug therapy. Dis of the Nervous System 1959; 20:452-457

32. Gulmann NC, Bahr B, Andersen B, Eliassen HMM: A double-blind trial of baclofen against placebo in the treatment of schizophrenia. Acta Psych Scand 1976; 54:287-293

33. Berger PA, Barchas JR: Pharmacology studies of betaendorphin in psychopathology. Psych Clin of North Amer 1983; 6:377-391

34. Pickar D, Wolkowitz OM, Doran AR, Labarca R, Roy A, Breier A, Narang PK: Clinical and biochemical effects of verapamil administration to schizophrenic patients. Arch of Gen Psych 1987; 44:113-118

35. Mattes JA, Hom W, Rochford JM: Cholecystokinin: A neuropeptide in the treatment of schizophrenia. Psychopharm Bulletin 1986; 22:119-122 
36. Ban TA, Lehmann HE, Deutsch M: Negative findings with mega-vitamins in schizophrenic patients: Preliminary report. Community Psychopharm 1977; 1:109-112

37. Brambilla F, Scarone S, Pugnetti L, Massironi R, Penati G: Bromocriptine therapy in chronic schizophrenia: Effects on symptomatology, sleep patterns, and prolactin response to stimulation. Psych Res 1983; 8:159-169

38. Tamminga CA, Gotts MD, Thaker GK, Alphs LD, Foster NL: Dopamine agonist treatment of schizophrenia with n-propylnorapomorphine. Arch of Gen Psych 1986; 43:398-402

39. Naber D, Munch U, Wissmann J, Gross R, Ritt R, Welter D: Naloxone treatment for five days ineffective in schizophrenia. Acta Psych Scand 1983; 67:265-271

40. Gitlin MJ, Gerner RH, Rosenblatt M: Assessment of naltrexone in the treatment of schizophrenia. Psychopharmacology 1981; 74:51-53

41. Inanaga K, Nakano T, Nagata T, Tanaka M, Ogawa N: Behavioral effects of protirelin in schizophrenia. Arch of Gen Psych 1978; 35:1011-1014

42. Linnoila M, Viukari M, Hietala O: Effect of sodium valproate on tardive dyskinesia. Brit JI of Psych 1976; 129:114-119

43. Iager AC, Kirch DG, Bigelow LB, Karson CN: Treatment of schizophrenia with a vasopressin analogue. Amer JI of Psych 1986; 143:375-377

44. Freedman R, Kirch DG, Bell J, Adler LE, Pecevich M, Pachtman E, Denver P: Clonidine treatment of schizophrenia: Double-blind comparison to placebo and neuroleptic drugs. Acta Psych Scand 1982; 65:35-45 